\title{
ВИРУЛЕНТНОСТЬ ПОПУЛЯЦИИ ВОЗБУДИТЕЛЯ КАРЛИКОВОЙ РЖАВЧИНЫ ЯЧМЕНЯ НА СЕВЕРНОМ КАВКАЗЕ В 2014-2017 гоДах
}

\author{
Г.В. ВОЛКОВА, А.В. ДАНИЛОВА, О.А. КУДИНОВА
}

Карликовая ржавчина (возбудитель Puccinia hordei Otth.) - вредоносное заболевание ячменя. При сильном поражении потери урожая могут составлять от 20 до 80 \%. Популяционные исследования патогена активно ведутся в странах, для которых защита от болезни особенно актуальна (Австралия, Новая Зеландия, США, страны Европы, Северной Африки). В настоящей работе мы изучили структуру северокавказской популяции возбудителя карликовой ржавчины ячменя (Puccinia hordei) по вирулентности, использовав 17 сортов-дифференциаторов и линий из международного и австралийского наборов, содержащих известные гены устойчивости к патогену. Материалом для исследований служили листья озимого ячменя (Hordeum vulgare L.) различных сортов, пораженные $P$. hordei и собранные на территории Северного Кавказа в период маршрутных обследований в 2014-2017 годах. Всего было выделено и проанализировано 208 монопустульных изолятов гриба. Растения ячменя, исползованные для тестирования изолятов, выращивали методом гидропоники с питательным раствором Кнопа. Большинство изолятов гриба были вирулентны для тестеров с генами $R p h 1, R p h 2, R p h 3, R p h 3+R p h 7, R p h 4, R p h 5, R p h 7$, $R p h 8, R p h 9+R p h 2$. На протяжении 4 лет мы не обнаружили изолятов, вирулентных в отношении линии с геном $R p h 13$. В 2016-2017 годах отмечалось снижение числа изолятов гриба, вирулентных для линий с генами $R p h 9$ и $R p h 19$, по сравнению с 2014-2015 годами и увеличение числа клонов, вирулентных для тестеров с генами $R p h 19+R p h 2, R p h 21+R p h 2$. Частота изолятов $P$. hordei, вирулентных в отношении сортов и линий ячменя с генами $R p h 5+R p h 2, R p h 6+R p h 2$, оставалась средней во все годы исследований. В 2016 году в связи с неблагоприятными для патогена условиями и сбором спорового материала с ограниченного набора сортов озимого ячменя, пораженных патогеном, частота изолятов, вирулентных для использованных сортов и линий, значительно снизилась. В 2014, 2015 и 2017 годах преобладали изоляты с большим числом аллелей вирулентности (от 11 до 15). Их доля составила соответственно 52,2; 39,5 и 50,0 \%. При этом доля изолятов, авирулентных в отношении всех используемым в анализе линий с генами $R p h$, составляла 1,$1 ; 2,1$ и 2,8 \%. В популяции гриба в 2016 году преобладали изоляты со средним и низким содержанием аллелей вирулентности. Значения индекса М. еi указывают на высокое сходство структуры северокавказской популяции патогена по вирулентности в 2014, 2015 и

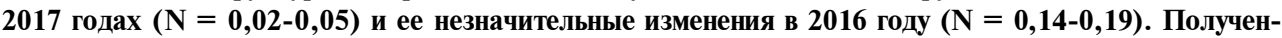
ные статистические результаты свидетельствуют о стабильности северокавказской популяции $P$. hordei по вирулентности. Ее разнообразие по частотам аллелей вирулентности на протяжении всего периода исследований было средним $\left(\mathrm{H}_{\mathrm{s}}=\mathbf{0 , 2 6 - 0 , 4 0 )}\right.$.

Ключевые слова: озимый ячмень, карликовая ржавчина, Puccinia hordei, вирулентность.

Карликовая ржавчина (возбудитель Puccinia hordei Otth.) - pacпространенное и вредоносное заболевание ячменя, приводящее к щуплости зерна и снижению урожайности. При сильном поражении растений потери урожая могут составлять более $20 \%$ (1). В мировом сельскохозяйственном производстве экономическое значение $P$. hordei зависит от региона возделывания культуры и варьирует по годам (2). За последние годы оно возросло (3). Особое влияние этот патоген имеет в регионах Востока и Среднего Запада США, Северной Африке, Новой Зеландии, Европе, Австралии и некоторых странах Азии (4). В ряде стран, особенно в тех регионах, где зерновые культуры созревают поздно, наблюдались значительные потери урожая на восприимчивых сортах $(5,6)$. В России карликовая ржавчина ячменя наиболее вредоносна в районах Поволжья, Северного Кавказа, Центрально-Черноземном районе, Западной и Восточной Сибири, на Дальнем Востоке, где она развивается практически ежегодно. Эпифитотии в Северо-Кавказском, Центрально-Черноземном районах и По-

\footnotetext{
* Исследования выполнены согласно Государственному заданию № 075-00376-19-00 Министерства науки и
} высшего образования РФ в рамках НИР по теме № 0686-2019-0008. 
волжье возникают с частотой 1-2 раза в 10 лет $(7,8)$.

Ведущая роль в разработке методов защиты ячменя принадлежит селекции и районированию высокопродуктивных сортов, устойчивых к заболеваниям, в том числе к карликовой ржавчине. Их создание и применение требует комплексного изучения генофонда устойчивости растенияхозяина и вирулентности патогена. На сегодняшний день известен 21 ген, обусловливающий ювенильную устойчивость (Rph1-Rph19, Rph21 и Rph22), и 3 гена возрастной устойчивости $(R p h 20, R p h 23$ и Rph24) $(9,10)$, обнаруженные у Hordeum vulgare, $H$. vulgare subsp. spontaneum и H. bulbosum.

Популяционные исследования патогена за рубежом активно ведутся в странах, для которых защита от болезни особенно актуальна. P.J. Cotterill c соавт. (11) показали, что большинство известных генов неэффективны против изолятов гриба, выявленных в Австралии с 1966 по 1995 год, и только гены $R p h 3$ и $R p h 7$ сохраняли эффективность. В дальнейшем в разных странах стали фиксировать изоляты $P$. hordei, вирулентные для линий с этим генами $(12,13)$. О вирулентности изолятов гриба в отношении линии с геном Rph15 сообщает Y. Sun (14). Тем не менее ген, полученный от дикого вида ячменя $H$. vulgare subsp. spontaneum, так же как и Rph16 (15), все еще относят к эффективным и активно используют в селекционных программах (16). Ювенильные гены Rph11 и Rph14 неэффективны, и изоляты, вирулентные для их носителей, встречаются во многих частях мира (17). В настоящее время $R p h 20, R p h 23$ и $R p h 24$ считаются эффективными генами устойчивости взрослых растений к P. hordei (18).

На территории бывшего СССР до 1964 года расовый и фенотипический состав $P$. hordei не изучался. Первые результаты исследований расового состава гриба, проведенные на наборе сортов-дифференциаторов, подобранном М.Н. Левиным и В.Д. Черевиком, опубликованы в 1968 году Э.М. Рогожиной с соавт. (19). Было обнаружено 18 рас, 16 из которых числились в международном регистре, а две (Х и У) - описаны впервые. В дальнейшем изучение расового разнообразия различных географических популяций патогена продолжилось $(20,21)$, и были выявлены еще две новые расы (1Л, 2Л) и две расы, числящиеся в международном регистре $(22,23)$.

В настоящем исследовании мы впервые установили, что большинство из монопустульных изолятов возбудителя карликовой ржавчины ячменя из северокавказской популяции вирулентны в отношении тестеров генов Rph1, Rph2, Rph3, Rph3 + Rph7, Rph4, Rph5, Rph7, Rph8, Rph9 + Rph2. Изоляты, вирулентные для линии с геном $R p h 13$, обнаружены не были.

Цель работы - изучение структуры северокавказской популяции возбудителя карликовой ржавчины ячменя (Puccinia hordei) по вирулентности.

Методика. Листья озимого ячменя (Hordeum vulgare L.) различных сортов, пораженные P. hordei, были собраны на территории Северного Кавказа при маршрутных обследованиях в 2014-2017 годах. Всего выделили и проанализировали 208 монопустульных изолятов гриба.

Выделение, размножение и дифференциацию монопустульных изолятов проводили по описанной методике (24). Растения ячменя выращивали на гидропонике с применением питательного раствора Кнопа (22).

Для оценки вирулентности гриба использовали 17 сортов-дифференциаторов и линий из международного и австралийского наборов (18), содержащих известные к настоящему времени гены устойчивости к патогену. Семена дифференциаторов проращивали в чашках Петри. Проросшие семена по 5 шт. высевали пинцетом в пластиковые вазоны объемом 25 мл с влажным песком. На 5-7-е сут инокулировали растения-дифференциа- 
торы водной суспензией спор $P$. hordei каждого монопустульного изолята. На 10-14-е сут оценивали типы реакции дифференциаторов (в баллах) по шкале Левина и Черевика. Растения с типами реакции 0, 0;, 1 и 2 балла относили к устойчивым, 3 и 4 балла - к восприимчивым. Если тип реакции был несколько выше или ниже указанных баллов, вводили дополнительные обозначения «+» или «-» (25).

Разнообразие популяции P. hordei по генам вирулентности описывали с помощью индекса Нея $\mathrm{H}_{\mathrm{s}}(26)$ :

$$
\mathrm{H}_{\mathrm{s}}(\mathrm{P})=\Sigma\left[1-\mathrm{q}_{i}^{2}-\left(1-\mathrm{q}_{i}\right)^{2}\right] / \mathrm{k}, 1 \leq i \leq \mathrm{k},
$$

где $\mathrm{q}_{i}$ - частота $i$-го аллеля в популяции, $\mathrm{k}-$ число аллелей.

Межпопуляционные различия (индекс Нея N) по частоте аллелей вирулентности гриба оценивали с помощью генетического расстояния (D) по М. Nei $(26,27)$ :

$$
\begin{gathered}
\mathrm{D}=-\ln \mathrm{IN}, \\
\mathrm{IN}=\Sigma \Sigma \mathrm{x}_{i j} \mathrm{y}_{i j} / \sqrt{\Sigma \Sigma \mathrm{X}_{i j}{ }^{2} \Sigma \Sigma \mathrm{y}_{i j}{ }^{2}},
\end{gathered}
$$

где $\mathrm{x}_{i j}$ и $\mathrm{y}_{i j}$ - частоты $i$-го аллеля, $j$-го года в сравниваемых популяциях х и у.

Статистическую обработку проводили в программе Statistica 10.0. («StatSoft, Inc.», США).

Результаты. Сорта-дифференциаторы и линии ячменя, использованные в работе, представлены в таблице 1.

1. Сорта-дифференциаторы и линии озимого ячменя (Hordeum vulgare L.) с известными генами устойчивости к карликовой ржавчине, использованные для изучения вирулентности изолятов северокавказской популяции Puccinia hordei Otth.

\begin{tabular}{l|l|l|c}
\hline Набор дифференциаторов & Coрт/линия & Происхождение & Ген(ы) устойчивости \\
\hline Международный & Sudan & C.I. 6489 & $R p h 1$ \\
Международный & Peruvian & Hordeum vulgare & $R p h 2$ \\
Международный & Estate & Hordeum vulgare & $R p h 3$ \\
Международный & Midas & Hordeum vulgare & $R p h 3+R p h 7$ \\
Международный & Gold & Hordeum vulgare & $R p h 4$ \\
Международный & Magnif 104 & Hordeum vulgare & $R p h 5$ \\
Австралийский дополнительный & Quinn & Mains Quinn, C.I. 1024 & $R p h 5+R p h 2$ \\
Международный & Bolivia & Hordeum vulgare & $R p h 6+R p h 2$ \\
Международный & Cebada Capa & Hordeum vulgare & $R p h 7$ \\
Международный & Egypt 4 & Hordeum vulgare & $R p h 8$ \\
Международный & Triumph & H. vulgare ssp. spontaneum & $R p h 12$ \\
Международный & Abyssinian & Hordeum vulgare & $R p h 9$ \\
Австралийский дополнительный & PI 531849 & H. vulgare ssp. spontaneum & $R p h 13$ \\
Австралийский дополнительный & Prior & Hordeum vulgare & $R p h 19$ \\
Австралийский дополнительный & Reka 1 & C.I. 5051 & $R p h 19+R p h 2$ \\
Австралийский дополнительный & Ricardo & Hordeum vulgare & $R p h 21+R p h 2$ \\
Австралийский дополнительный & Cantala & Hordeum vulgare & $R p h C$ \\
\hline
\end{tabular}

В 2014, 2015 и 2017 годах сложились благоприятные условия для развития патогена, в то время как 2016 год был неблагоприятным по погодным условиям.

На протяжении четырех лет изучения абсолютную эффективность показал ген Rph13 (табл. 2). Источник происхождения этого гена - дикий вид ячменя $H$. vulgare ssp. spontaneum. Однако, несмотря на его эффективность на Северном Кавказе, в ряде регионов мира выявлены изоляты, вирулентные для носителей этого гена (18). Большинство тестеров с генами устойчивости $R p h 1, R p h 2, R p h 3, R p h 3+R p h 7, R p h 4, R p h 5, R p h 7$, $R p h 8, R p h 9+R p h 2$ поражались изолятами северокавказской популяции P. hordei с высокой частотой во все годы изучения. В 2016-2017 годах по сравнению с 2014-2015 годами отмечалось снижение числа изолятов гриба, вирулентных для линий с генами $R p h 9, R p h 19$, и увеличение числа клонов, вирулентных в отношении тестеров с генами $R p h 19+\operatorname{Rph} 2, \operatorname{Rph} 21+R p h 2$. Численность изолятов, вирулентных для сортов и линий ячменя с генами 
$R p h 5+R p h 2, R p h 6+R p h 2$, оставалась средней во все годы исследований. В 2016 году в связи с неблагоприятными для патогена условиями и сбором спорового материала с ограниченного набора сортов, пораженных патогеном, частота изолятов, вирулентных к сортам и линиям ячменя, была значительно ниже.

2. Частота изолятов, вирулентных для линий и сортов озимого ячменя (Hordeum vulgare L.) с генами Rph, в северокавказской популяции Puccinia hordei Otth. по годам наблюдений

\begin{tabular}{|c|c|c|c|c|}
\hline \multirow{2}{*}{ Тестеры с $R p h$-генами } & \multicolumn{4}{|c|}{ Частота, \% } \\
\hline & 2014 год & 2015 год & 2016 год & 2017 год \\
\hline Rph 1 & 76,1 & 60,5 & 51,3 & 83,3 \\
\hline $\operatorname{Rph} 2$ & 75,0 & 73,7 & 33,3 & 72,2 \\
\hline Rph3 & 81,5 & 63,2 & 15,4 & 80,6 \\
\hline$R p h 3+R p h 7$ & 79,3 & 60,5 & 20,5 & 86,1 \\
\hline Rph4 & 68,5 & 63,2 & 28,2 & 83,3 \\
\hline Rph5 & 73,9 & 55,3 & 30,8 & 75,0 \\
\hline Rph5 + Rph2 & 30,4 & 50,0 & 35,9 & 36,1 \\
\hline Rph6 + Rph2 & 34,8 & 36,8 & 12,8 & 47,2 \\
\hline $\operatorname{Rph} 7$ & 80,4 & 55,3 & 15,4 & 83,3 \\
\hline $\operatorname{Rph} 8$ & 78,3 & 57,9 & 25,6 & 88,9 \\
\hline Rph 9 & 56,5 & 47,4 & 2,6 & 8,3 \\
\hline Rph 12 & 50,0 & 52,6 & 5,1 & 38,9 \\
\hline Rph 13 & 0,0 & 0,0 & 0,0 & 0,0 \\
\hline Rph 19 & 26,1 & 10,5 & 2,6 & 8,3 \\
\hline$R p h 19+R p h 2$ & 42,4 & 50,0 & 46,2 & 86,1 \\
\hline Rph $21+R p h 2$ & 0,0 & 0,0 & 0,0 & 25,0 \\
\hline Rph $C$ & 41,3 & 34,2 & 2,6 & 75,0 \\
\hline Число изолятов, шт. & 92 & 38 & 39 & 39 \\
\hline $\begin{array}{l}\text { Индекс внутрипопуляци- } \\
\text { онного разнообразия } \mathrm{H}_{\mathrm{s}}\end{array}$ & 0,36 & 0,40 & 0,26 & 0,30 \\
\hline
\end{tabular}

Следовательно, большинство известных в настоящее время генов устойчивости были неэффективны против P. hordei во все годы исследований. Высокую эффективность сохранял ген $R p h 13$, по которому не было выявлено вирулентных изолятов, начиная с 2012 года $(8,21)$.

Статистический анализ разнообразия популяции патогена по частотам аллелей вирулентности показал, что наименее разнообразной была популяция в 2016 году $\left(\mathrm{H}_{\mathrm{s}}=0,26\right)$, что определили неблагоприятные для патогена условия этого сезона (табл. 2). В целом, разнообразие северокавказской популяции $P$. hordei оставалось средним $\left(\mathrm{H}_{\mathrm{s}}=0,26-0,40\right)$ по частотам аллелей вирулентности на протяжении всего периода исследований.

3. Частота изолятов с разным числом аллелей вирулентности в отношении использованных линий и сортов озимого ячменя (Hordeum vulgare L.) в северокавказской популяции Puccinia hordei Otth. по годам наблюдений

\begin{tabular}{l|c|c|c|c}
\hline \multirow{2}{*}{ Число аллелей вирулентности } & \multicolumn{4}{|c}{ Доля изолятов с разным числом аллелей вирулентности, \% } \\
\cline { 2 - 5 } & 2014 год & 2015 год & 2016 год & 2017 год \\
\hline 0 & 1,1 & 2,1 & 30,8 & 2,8 \\
$1-5$ & 22,8 & 28,9 & 35,9 & 11,1 \\
$6-10$ & 23,9 & 26,3 & 33,3 & 36,1 \\
$11-15$ & 52,2 & 39,5 & 0,0 & 50,0 \\
Число изолятов, шт. & 92 & 38 & 39 & 39 \\
\hline
\end{tabular}

Анализ динамики частот изолятов $P$. hordei по числу аллелей вирулентности показал, что в 2014, 2015 и 2017 годах в популяции патогена преобладали изоляты с большим числом аллелей вирулентности (от 11 до 15) (табл. 3). При этом доля изолятов, авирулентных в отношении всех использованных нами линий с генами $R p h$, составляла от 1,1 до $2,8 \%$. В 2016 году на изоляты гриба со средним и низким числом аллелей вирулентности приходилось 33,3-35,9 \% и не были выявлены изоляты P. hordei 
с высоким числом аллелей вирулентности (11-15 генов). При этом почти треть изолятов были авирулентными в отношении всех изученных тестеров с генами $R p h$.

Уменьшение числа аллелей вирулентности и снижение их частот к большинству тестеров могло быть следствием неблагоприятных для развития патогена погодных условий, которые сложились в вегетационный сезон 2016 года. В среднем развитие $P$. hordei по региону не превысило $5 \%$, споровый материал был собран с ограниченного набора сортов озимого ячменя, пораженных патогеном, что также могло повлиять на снижение разнообразия популяции патогена. Полученные результаты согласуются с существующей теорией о том, что при наступлении неблагоприятных условий выживают изоляты с минимальным числом аллелей вирулентности. Это связано с тем, что обилие «лишних» аллелей влияет на жизнеспособность возбудителей ржавчинных болезней. В благоприятных для патогена условиях, наоборот, преобладают изоляты со средним и высоким числом аллелей вирулентности (28).

Значения индекса Нея N, характеризующего различия между популяциями, указывают на высокое сходство структуры северокавказской популяции патогена по вирулентности в 2014, 2015 и 2017 годах ( $\mathrm{N}=0,02$ $0,05)$ и ее незначительные изменения в 2016 году $(0,14-0,19)$ (рис.). Выявленная дифференциация может быть обусловлена причинами, описанными выше.

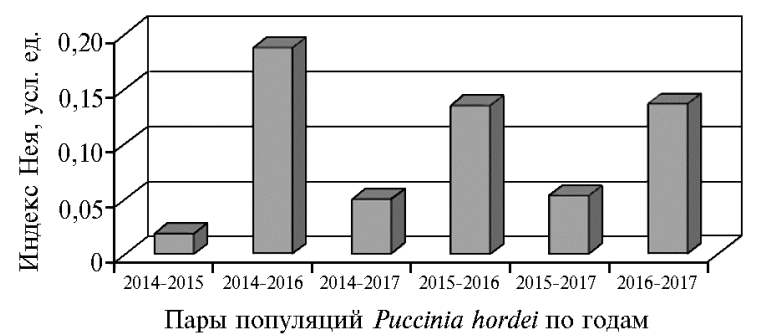

Значения индекса Нея $\mathrm{N}$, характеризующего различия между северокавказскими популяциями Puccinia hordei Otth. по частоте аллелей вирулентности в разные годы.
Сравнение частоты изолятов северокавказской популяции P. hordei, вирулентных для носителей генов $R p h$, с данными, полученными другими исследователями, свидетельствует о несовпадении эффективности большинства генов устойчивости. Так, в Австралии сохраняют эффективность гены Rph7, Rph11, Rph14, Rph15, Rph18 (29) и картированный позднее ген $R p h 21$ (23). Ген $R p h 3$ сохранял свою эффективность в Австралии, начиная с 1992 года (9), но в 2009 году были обнаружены изоляты, вирулентные для линий с этим геном (30). В Европе эффективными генами считаются $\operatorname{Rph} 7$ и $\operatorname{Rph} 16(2,3)$, в Эфиопии - Rph3 и Rph7 (31). Частота изолятов северокавказской популяции $P$. hordei, вирулентных в отношении носителей генов $R p h 3$ u $R p h 7$, составляла от 15,4 \% до 83,3 \% (см. табл. 2). Ген Rph 13, эффективный против северокавказской популяции патогена, неэффективен в Европе и Австралии $(3,9,29)$.

Таким образом, различия по вирулентности северокавказской популяции Puccinia hordei Otth. в 2014, 2015 и 2017 годах были несущественными $(\mathrm{N}=0,02-0,05)$, что свидетельствует о ее стабильности по этому признаку. В неблагоприятном для патогена 2016 году отмечены незначительные внутрипопуляционные изменения $(\mathrm{N}=0,14-0,19)$. На протяжении четырех лет не были обнаружены изоляты, вирулентные для линии с геном Rph 13. Большинство изолятов популяции гриба оказалось насыщено вирулентными аллелями. Разнообразие северокавказской популяции $P$. hor$d e i$ по частотам аллелей вирулентности $\left(\mathrm{H}_{\mathrm{s}}\right)$ оставалось в пределах от 0,26 до 0,40$)$ на протяжении всего периода исследований. 
Авторы благодарят сотрудников лаборатории иммунитета зерновых культур $\kappa$ грибным болезням О.Ф. Ваганову, И.П. Матвееву, а также сотрудника лаборатории фитосанитарного мониторинга, приборного и технического обеспечения Р.Ю. Данилова (ФГБНУ Всероссийский НИИ биологической защиты растений) за оказанную помощь в проведении исследований.

\title{
ФГБНУ Всероссийский НИИ биологической защиты растений, \\ Поступила в редакцию \\ 19 апреля 2019 года
}

350039 Россия, г. Краснодар, ул. Вавилова, 14,

e-mail: steight@mail.ru $\varangle$, galvol.bpp@yandex.ru, alosa@list.ru

Sel'skokhozyaistvennaya biologiya [Agricultural Biology], 2019, V. 54, № 3, pp. 589-596

\section{THE VIRULENCE OF THE BARLEY LEAF RUST PATHOGEN IN THE NORTH CAUCASUS IN 2014-2017}

\author{
G.V. Volkova, A.V. Danilova, O.A. Kudinova
}

\begin{abstract}
All-Russian Research Institute of Biological Plant Protection, 14, ul. Vavilova, Krasnodar, 350039 Russia, e-mail steight@mail.ru (凹 corresponding author), galvol.bpp@yandex.ru, alosa@list.ru

ORCID:

Volkova G.V. orcid.org/0000-0002-3696-2610 Kudinova O.A. orcid.org/0000-0002-0568-4312

Danilova A.V. orcid.org/0000-0002-6009-9757

The authors declare no conflict of interests

Acknowledgements:

The authors thank O.F. Vaganov, I.P. Matveev (Laboratory of the immunity of cereals to fungal diseases, AllRussian Research Institute of Biological Plant Protection), and R.Yu. Danilov (Laboratory of phytosanitary monitoring, instrumentation and technical support, All-Russian Research Institute of Biological Plant Protection) for their assistance in the research.

Carried out in accordance with the State task No. 075-00376-19-00 of the Ministry of Science and Higher Education of the Russian Federation as a part of the research work on subject No. 0686-2019-0008

Received April 19, 2019

doi: 10.15389/agrobiology.2019.3.589eng
\end{abstract}

\section{Abstract}

Barley leaf rust caused by Puccinia hordei Otth. is a harmful disease of barley. If the crop is severely damaged, the yield loss may be of 20 to $80 \%$. Population studies of the pathogen abroad are actively conducted in countries for which protection against the disease is of particular importance (Australia, New Zealand, the United States, Europe, the countries of Northern Africa). This paper describes the North Caucasian P. hordei population virulence in 2014-2017 to 17 differentiator varieties and barley lines of international and Australian kits containing currently known pathogen resistance genes, shows. Winter barley leaves (Hordeum vulgare L.) of different varieties affected by $P$. hordei which were collected during route surveys in 2014-2017 in the territory of the North Caucasus served as a biomaterial. The selection and reproduction of mono-pustule isolates was carried out according to the common procedure. Barley plants were grown hydroponically with the use of Knop's nutrient solution. To assess the virulence of the fungus, 17 varieties-differentiators and lines from the international and Australian sets containing the currently known genes of resistance to the pathogen were used. A total of 208 mono-pustule isolates of the fungus were analyzed most of which were virulent to the testers with $R p h$ genes, the $R p h 1, R p h 2, R p h 3, R p h 3+R p h 7, R p h 4, R p h 5, R p h 7$, $R p h 8, R p h 9+R p h 2$. During the four years of study, no isolates virulent to the line with $R p h 13$ gene were detected. In 2016-2017 as compared to 2014-2015, there was a decrease in the number of isolates virulent to the lines with genes $R p h 9$, Rph19, and an increase in clones virulent to testers with genes $R p h 19+R p h 2, R p h 21+R p h 2$. The frequency of $P$. hordei isolates that are virulent to varieties and lines of barley with genes $R p h 5+R p h 2, R p h 6+R p h 2$ remained moderate throughout all the years of the research. In 2016, due to unfavorable conditions for the pathogen and the collection of spore material from a limited set of winter barley varieties affected by the pathogen, the frequency of isolates virulent to varieties and lines of barley significantly reduced. In 2014, 2015 and 2017, isolates with a large number of virulence alleles, from 11 to 15 , prevailed in the population and reached $52.2 \%, 39.5 \%$ and $50.0 \%$, respectively. The portion of isolates, avirulent to all used plants with genes $R p h$, was $1.1 \%, 2.1 \%$ and $2.8 \%$, respectively. In 2016, the fungal isolates with moderate and low virulence alleles prevailed. The Nei index indicates a high similarity of the structure of North Caucasian pathogen population by virulence in 2014, 2015 and $2017(\mathrm{~N}=0.02-0.05)$ and its minor changes in $2016(\mathrm{~N}=0.14-0.19)$. The obtained statistical results indicate the stability of the North Caucasian $P$. hordei population by virulence. The level of its diversity in the frequency of virulence alleles remained medium $\left(\mathrm{H}_{\mathrm{s}}=0.26-0.40\right)$ throughout the entire study period.

Keywords: winter barley, leaf rust, Puccinia hordei, virulence. 


\section{R E F E R E N C E S}

1. Kuznetsova T.E., Serkin N.V. Selektsiya yachmenya na ustoichivost' $k$ boleznyam: monografiya [Barley breeding for disease resistance: a monograph]. Krasnodar, 2006 (in Russ.).

2. Niks R.E., Walther U., Jaiser H., Martinez F., Rubiales D. Resistance against barley leaf rust (Puccinia hordei) in West European spring barley germplasm. Agronomie, 2000, 20(7): 769-782 (doi: 10.1051/agro:2000174).

3. Czembor H.J., Czembor J.H. Leaf rust resistance in winter barley cultivars and breeding lines. Plant Breed. Seed Sci., 2007, 56: 47-56.

4. Compendium of barley diseases . D.E. Mathre (ed.). The American Phytopathological Society, St. Paul, MN, 1982: 32-41.

5. Shtaya M.J.Y., Sillero J.C., Rubiales D. Search for partial resistance against Puccinia hordei in barley landraces from the Fertile Crescent. Plant Breeding, 2006, 125: 343-346 (doi: 10.1111/j.14390523.2006.01239.x).

6. Woldeab G., Fininsa C., Singh H., Yuen J. Virulence spectrum of Puccinia hordei in barley production systems in Ethiopia. Plant Pathology, 2006, 55: 351-357 (doi: 10.1111/j.13653059.2006.01357.x).

7. Karlikovaya rzhavchina yachmenya [Barley dwarf rust]. Available https://rosselhoscenter.com/2014-02-28-11-39-42/2011-11-16-12-58-47/vozbuditeliboleznej/1754-karlikovaya-rzhavchina-yachmenya. Accessed 24.09.2018 (in Russ.).

8. Danilova A.V., Volkova G.V. Zashchita i karantin rastenii, 2015, 7: 46-48 (in Russ.).

9. Park R.F. Pathogenic specialization and pathotype distribution of Puccinia hordei in Australia, 1992 to 2001. Plant Disease, 2003, 87(11): 1311-1316 (doi: 10.1094/PDIS.2003.87.11.1311).

10. Singh D., Dracatos P., Derevnina L., Zhou M., Park R.F. Rph23: a new designated additive adult plant resistance gene to leaf rust in barley on chromosome 7H. Plant Breeding, 2014, 134(1): 62-69 (doi: 10.1111/pbr.12229).

11. Cotterill P.J., Park R.F., Rees R.G. Pathogenic specialization of Puccinia hordei Otth. in Australia, 1966-1990. Australian Journal of Agricultural Research, 1995, 46(1): 127-134 (doi: 10.1071/AR9950127).

12. Cromey M.G., Viljanen-Rollinson S. Virulence of Puccinia hordei on barley in New Zealand from 1990 to 1993. New Zealand Journal of Crop and Horticultural Science, 1995, 23(2): 115-119 (doi: 10.1080/01140671.1995.9513877).

13. Shtaya M.J.Y., Sillero J.C., Rubiales D. Screening for resistance to leaf rust (Puccinia hordei) in a collection of Spanish barleys. Breeding Science, 2006, 56: 173-177 (doi: 10.1270/jsbbs.56.173).

14. Sun Y. Study of Puccinia hordei and its host resistances in Hordeum vulgare. PhD Thesis. North Dakota State Univ, Fargo, ND, 2007.

15. Perovic D., Stein N., Zhang H., Drescher A., Prasad M., Kota R., Kopahnke D., Graner A. An integrated approach for comparative mapping in rice and barley with special reference to the Rph 16 resistance locus. Functional \& Integrative Genomics, 2004, 4(2): $74-83$ (doi: 10.1007/s10142003-0100-z)

16. Bernardo L., Prinsi B., Negri A.S., Cattivelli L., Espen L., Valè G. Proteomic characterization of the Rph15 barley resistance gene-mediated defense responses to leaf rust. BMC Genomics, 2012, 13: 642-658 (doi: 10.1186/1471-2164-13-642).

17. Fetch T.G., Steffenson B.J., Jin Y. Worldwide virulence of Puccinia hordei on barley. Phytopathology, 1998, 88: 28-34.

18. Park R.F., Golegaonkar P.G., Derevnina L., Sandhu K.S., Karaoglu H., Elmansour H.M., Dracatos P.M., Singh D. Leaf rust of cultivated barley: pathology and control. Annual Review of Phytopathology, 2015, 53: 565-589 (doi: 10.1146/annurev-phyto-080614-120324).

19. Rogozhina E.M., Trofimovskaya L.Ya. V sbornike: Byulleten' VIR [In: VIR newsletter]. Leningrad, 1968: 58-63 (in Russ.).

20. Shchelko L.G. Trudy po prikladnoi botanike, genetike i selektsii, 1974, 53(2): 105-112 (in Russ.).

21. Danilova A.V., Volkova, G.V., Danilov R.Yu. Politematicheskii setevoi elektronnyi nauchnyi zhurnal KubGAU, 2014, 7(101). Available http://ej.kubagro.ru/2014/07/pdf/73.pdf. No date (in Russ.).

22. Smirnova L.A., Alekseeva T.P. Usovershenstvovannyi metod vyrashchivaniya vskhodov zernovykh kul'tur dlya immunologicheskikh issledovanii: metodicheskie rekomendatsii po izucheniyu rasovogo sostava vozbuditelei rzhavchiny khlebnykh zlakov [Improved method of growing seedlings of cereals for immunological research: guidelines for the study of the race composition of cereal rust pathogens]. Moscow, 1988 (in Russ.).

23. Sandhu K.S., Forrest K.L., Kong S., Bansal U.K., Singh D., Hayden M.J., Park R.F. Inheritance and molecular mapping of a gene conferring seedling resistance against Puccinia hordei in the barley cultivar Ricardo. Theoretical and Applied Genetics, 2012, 125(7): 1403-1411 (doi: 10.1007/s00122-012-1921-8).

24. Anpilogova L.K., Volkova G.V. Metody sozdaniya iskusstvennykh infektsionnykh fonov $i$ otsenki sortoobraztsov pshenitsy na ustoichivost' $k$ vredonosnym boleznyam (fuzariozu kolosa, rzhavchinam, 
muchnistoi rose) [Artificial infectious methods and assessing wheat varieties for resistance to harmful diseases (ear fusarium, rust, powdery mildew)]. Krasnodar, 2000 (in Russ.).

25. Babayants L., Meshterkhazi A., Vekhter F., Neklksa N., Dubinina L., Omel'chenko L., Klechkovskaya E., Slyusarenko A., Bartosh P. Metody selektsii $i$ otsenki ustoichivosti pshenitsy $i$ yachmenya $k$ boleznyam $v$ stranakh-chlenakh SEV [Methods of breeding and assessing the resistance of wheat and barley to diseases in the CMEA member countries]. Praga, 1988 (in Russ.).

26. Nei M. Estimation of average heterozygosity and genetic distance from a small number of individuals. Genetics, 1978, 89(3): 583-590.

27. Kosman E., Leonard K.J. Conceptual analysis of methods applied to assessment of diversity within and distance between populations with asexual or mixed mode of reproduction. New Phytologist, 2007, 174(3): 683-696 (doi: 10.1111/j.1469-8137.2007.02031.x).

28. D'yakov Yu.T. Populyatsionnaya biologiya fitopatogennykh gribov [Population biology of phytopathogenic fungi]. Moscow, 1998 (in Russ.).

29. Sandhu K.S., Singh D., Park R.F. Characterization of leaf rust resistance in international barley nurseries. Journal of Plant Breeding and Crop Science, 2016, 8(8): 117-125 (doi: 10.5897/JPBCS2016.0587).

30. Park R.F., Williams M. Barley leaf rust (caused by Puccinia hordei). In: 2010-2011 Cereal Rust Survey - Annual Report. The University of Sydney, Plant Breeding Institute, Cobbitty, 2010: 7 8. Available https://sydney.edu.au/content/dam/corporate/documents/sydney-institute-ofagriculture/research/plant-breeding-and-production/cereal_rust_survey_2010_11.pdf. No date.

31. Woldeab G., Fininsa C., Singh H., Yuen J. Virulence spectrum of Puccinia hordei in barley production systems in Ethiopia. Plant Pathology, 2006, 55(3): 351-357 (doi: 10.1111/j.13653059.2006.01357.x). 